\title{
Assessment of the Hygienic Quality of Meals Served in Hospital: Case of the Main Hospital of Dakar (Senegal)
}

\author{
Abdelsalam Adoum Doutoum (Corresponding author) \\ Higher National Institute of Science and Technology of Abeche \\ P.O. Box 130 Abeche, Chad \\ Inter-State School of Veterinary Sciences and Medicine (EISMV)-Hygiene and \\ Foodstuffs Industry of Animal Origin (HIDAOA), Dakar, Senegal \\ Tel: 235-9919-8019/6373-8173Ｅ-mail: doutoum3000@yahoo.fr
}

\section{Djamalladine Mahamat Doungous}

Higher National Institute of Science and Technology of Abeche

P.O. Box 130 Abeche, Chad

Tel: 235-6347-4969 / 9004-2065_E-mail: djadas2007@yahoo.fr

\author{
Abdelsalam Tidjani \\ Faculty of Human Health Sciences, University of N'Djamena \\ P.O. Box 1117, N’Djamena, Chad \\ Tel: 235-9574-2125 / 6635-2119 E-mail: abdelti@yahoo.fr
}

Hamadou Abba

Faculty of Health Sciences of Adam Barka University of Abeche (Chad)

Balde Jupiter

Inter-State School of Veterinary Sciences and Medicine (EISMV)-Hygiene and Foodstuffs Industry of Animal Origin (HIDAOA), Dakar, Senegal 


\section{Coumba Faye}

Inter-State School of Veterinary Sciences and Medicine (EISMV)-Hygiene and Foodstuffs Industry of Animal Origin (HIDAOA), Dakar, Senegal

\section{Mamadou Balde}

Inter-State School of Veterinary Sciences and Medicine (EISMV) -Hygiene and Foodstuffs Industry of Animal Origin (HIDAOA), Dakar, Senegal

E-mail: Baldemamadou4@yahoo.fr

\section{Roumane Moukhtar}

Higher National Institute of Science and Technology of Abeche

P.O. Box 130 Abeche, Chad

Tel: 235-9947-2656_E-mail: roumane_moukhtar@yahoo.fr

Marius K. Somda

Center for Research in Biological, Food and Nutritional Sciences (CRSBAN)

Department of Biochemistry-Microbiology (DBM), University Ouaga 1 Pr Joseph KI-ZERBO, 03 P.O. Box 7021, Ouagadougou 03, Burkina Faso

\section{Malang Seydi}

Inter-State School of Veterinary Sciences and Medicine (EISMV) -Hygiene and Foodstuffs Industry of Animal Origin (HIDAOA), Dakar, Senegal

E-mail:mgseydi@yahoo.fr

Bhen Sikina Toguebaye

Department of Animal Biology; Cheikh Anta Diop University of Dakar (Senegal)

Alfred S. Traore

Center for Research in Biological, Food and Nutritional Sciences (CRSBAN)

Department of Biochemistry-Microbiology (DBM), University Ouaga 1 Pr Joseph KI-ZERBO, 03 P.O. Box 7021, Ouagadougou 03, Burkina Faso 


\section{Mll Macrothink}

Received: December 25, 2018

doi:10.5296/jfs.v8i1.14635
Accepted: April 2, 2019 Published: April 9, 2019

URL: https://doi.org/10.5296/jfs.v8i1.14635

\begin{abstract}
Hospitals have an optimal growth conditions for some germs, because of the high relative humidity and relatively high temperature. These germs, which are found in foods served in hospitals, could cause food poisoning in hospitalized patients. To help improve the hygienic quality of meals and to prevent risks related to social catering, we have chosen to conduct a study on the microbiological quality of meals served at the Main Hospital of Dakar. A total of 100 samples of hot meals were processed in the food microbiology laboratory of the Inter-State School of Veterinary Sciences and Medicine (EISMV) in Dakar. The following results were obtained: $56 \%$ of unsatisfactory samples, $40 \%$ are acceptable, $4 \%$ unsatisfactory, according to the microbiological criteria of the French Republic, which must satisfy certain animal or animal products. For the various flora sought, the percentages of samples exceeding the acceptability threshold are as follows: $10 \%$ for the total flora, $35 \%$ for the faecal coliforms, $1 \%$ for the sulfito-reducting anaerobes. Meals are fairly contaminated by fecal coliforms. It is therefore clear that the rate of bacterial contamination of meals is quite high, especially by fecal coliforms.
\end{abstract}

Keywords: Meal, Hospital, Environment, Hygienic quality, Bacteria

\title{
1. Introduction
}

Hygiene and food safety is very important in a hospital because patients in the hospital are the higher risk group of foodborne illness. Unsafe foods cause complication to patients affecting reputation to hospital, economic losses, legal action by authority and negative impacts to organization. Food hazards may cause Biological, Chemical, Physical and Allergenic Hazards and consequences to patient and patient party. It's ironical to state that, awareness on food safety is of poor standard among food handlers working in canteen, hotel or cafeteria situated in hospital or hospital premises. Food handlers in hospitals contribute to the incidence of foodborne disease to consumers; therefore, it is essential that workers and management staff have a thorough understanding of safe food practices since hospitalized patients and patient party are more vulnerable to potential hazards, and neglecting these principles can lead to increased morbidity and mortality (Bhattarai \& Yadav, 2018). In addition to providing care, hospitals provide a variety of other services for the benefit of hospitalized patients, such as restoring them. Since the rehabilitation of the patient and his comfort are the main objectives of the hospital restoration. Therefore, hygiene in the food sector has, a particular importance in hospitals (Assmi et al., 2005). On the one hand, because microorganisms can proliferate in the kitchen reach you dangerous threshold, there reigns optimal growth conditions, that is to say a high relative humidity and a high temperature (Nicolas, 2008; Nifaoui, 2015). On the other hand, because of his illness, the patient is more susceptible to toxic infections than other sections of the population. Finally, hospital catering has certain specificity; this is due to the fact that it is addressed to a temporarily captive clientele that did not choose his menu and who 
did not come to the hospital to eat (Hamza et al., 1999). Food handlers may also carry some human specific foodborne pathogens such as Hepatitis A, Noroviruses, typhoidal Salmonella, Staphylococcus aureus and Shigella sp in their hands, cuts or sores, mouth, skin and hair (Sharif, Obaidat \& Al-Dalalah, 2013). Food handlers may also shed foodborne pathogens, such as E. coli $\mathrm{O} 157: \mathrm{H} 7$ and non-typhoidal Salmonella during the infectiousness period or less important during recovery period of a gastrointestinal sickness (Adams \& Moss, 2008). Restoration hygiene referred to all measures and precautions that must be taken to avoid contamination of meals Quality must be a major concern, especially since the hospital has long suffered from a bad reputation for restoration (Assmi et al., 2005; Hamza et al., 1999). But this is not always satisfactory at the level of the Main Hospital of Dakar. In order to contribute to the improvement of the hygienic quality of meal sand to prevent risks related to social catering, we have chosen to carry out a study on the microbiological characteristics of meals served in the main hospital of Dakar.

\section{Materials and Methods}

\subsection{Sampling}

Sterile materials were used for sampling. Meals were collected at 2 levels at the Dakar main hospital: first at the central kitchen in the various pots at the beginning and at the end of the service; second, at the hospital units during the distribution of meals to patients. Sampling was carried out on the various foods (meat, vegetables, sauce) making up the menu and then placed in an aluminum bowl conditioned in Pasteur-sterilized Kraft paper. The samples were then placed in a cooler containing dry ice and transported directly to the laboratory.

\subsection{Laboratory Analysis}

The samples and laboratory analyzes were carried out in accordance with the ISO 6579: 2002 standard. The samples were processed before analysis in the laboratory. A solution was prepared (buffered peptone water) from each sample. Dilutions of each solution were prepared and served to bacterial culture, and allow bacterial counting. The bacterial culture specifically looked for total aerobic mesophilic flora (FMAT) bacteria (Plate Count Agar at $30{ }^{\circ} \mathrm{C}$ ), thermotolerant faecal coliforms (VRBL agar at $44{ }^{\circ} \mathrm{C}$ ), sulfite-reducing Anaerobes (Trypticase Sulfite Neomycin at $46^{\circ} \mathrm{C}$ ), presumptive pathogenic Staphylococci (Baird Parker at $37^{\circ} \mathrm{C}$ ) and Salmonella (Rappaport Vassiliadis, Bright Green and Hektoen at $37-42{ }^{\circ} \mathrm{C}$. Fungal flora count (FF) was also performed (oxytetracycline-glucose at $20-25^{\circ} \mathrm{C}$ ).

\subsection{Results Interpretation}

The interpretation of the results of the microbiological analyses was carried out on the basis of the criteria defined by the French standards (2006). These criteria are defined by the ministerial decree of 21 December 1979 revised of 27 April 2006 (République Française, 2006).

\section{Results and Discussion}

\subsection{Results of Microbiological Analysis}

We analysed a total of 100 food samples. Regarding the quality of the samples and based on French standards (République Française, 2006), the study that we have led showed that $55 \%$ of the samples collected are satisfactory; $4 \%$ are acceptable; while $41 \%$ are unsatisfactory.

\subsubsection{Assessment of Results According to the Type of Germs}




\section{Macrothink}

3.1.1.1 Total Aerobic Mesophile Flora at $30^{\circ} \mathrm{C}$

The different levels of contamination by the total flora are given in Table 1 .

Table 1. Contamination levels by total flora at $30{ }^{\circ} \mathrm{C}$

\begin{tabular}{lllll}
\hline Contamination level (germs/g) & Number of samples & Averages & Minimum & Maximum \\
\hline $\mathrm{F} \leq 3 \times 10^{5}$ & 79 & $48 \times 10^{3}$ & 105 & $3 \times 10^{5}$ \\
$3 \times 10^{5}<\mathrm{F} \leq 9 \times 10^{5}$ & 10 & $49 \times 10^{4}$ & $32 \times 10^{4}$ & $71 \times 10^{4}$ \\
$9 \times 10^{5}<\mathrm{F} \leq 3 \times 10^{6}$ & 1 & $\sim$ & $\sim$ & $\sim$ \\
$\mathrm{F}>3 \times 10^{6}$ & 10 & $\sim$ & $\sim$ & $\sim$ \\
\hline
\end{tabular}

$\mathrm{F}=$ flora.

Table 1 shows that:

$\checkmark 89 \%$ of the samples are satisfactory (contamination rate less than $3 \mathrm{~m}(\mathrm{~m}=3.105$ being the benchmark));

$\checkmark \quad 1 \%$ of samples are acceptable;

$\checkmark \quad 10 \%$ are unsatisfactory.

\subsubsection{Fecal or Thermo-Tolerant Coliforms at $44{ }^{\circ} \mathrm{C}$}

The levels of contamination by coliforms are shown in Table 2 .

Table 2. Levels of contamination by fecal coliforms

\begin{tabular}{lllll}
\hline Contamination level germs/g & Number of samples & Averages & Minimum & Maximum \\
\hline Absence & 57 & $\sim$ & $\sim$ & $\sim$ \\
$\mathrm{F} \leq 10$ & 4 & 10 & $\sim$ & $\sim$ \\
$10<\mathrm{F} \leq 30$ & 2 & 30 & $\sim$ & $\sim$ \\
$30<\mathrm{F} \leq 10^{2}$ & 2 & 50 & 40 & 60 \\
$\mathrm{~F}>10^{2}$ & 35 & $23 \times 10^{2}$ & $12 \times 10^{2}$ & $3 \times 10^{4}$ \\
\hline
\end{tabular}

$\mathrm{F}=$ flora.

Table 2 shows that for fecal coliforms:

$\checkmark \quad 63 \%$ of samples are satisfactory (rate $<30$ );

$\checkmark 2 \%$ are acceptable;

$\checkmark \quad 35 \%$ are unsatisfactory.

3.1.1.3 Fungic Flora (Yeasts and Molds)

The different levels of contamination by yeasts and molds are shown in Table 3 . 


\section{Macrothink}

Table 3. Levels of contamination by fungal flora

\begin{tabular}{lllll}
\hline Contamination level germs/g & Number of samples & Averages & Minimum & Maximum \\
\hline Absence & 42 & - & - & - \\
$\mathrm{F} \leq 5 \times 10^{2}$ & 46 & 90 & 10 & $47 \times 10^{1}$ \\
$5 \times 10^{2}<\mathrm{F} \leq 1.5 .10^{3}$ & 7 & $98 \times 10^{1}$ & $6 \times 10^{2}$ & $13 \times 10^{2}$ \\
$1.5 \times 10^{3}<\mathrm{F} \leq 5.10^{3}$ & 5 & $25 \times 10^{2}$ & $16 \times 10^{2}$ & $41 \times 10^{2}$ \\
$\mathrm{~F}>5 \times 10^{3}$ & - & - & - & - \\
\hline $\mathrm{F}=$ flora. & & & &
\end{tabular}

Table 3 shows that for the fungal flora:

$\checkmark 95 \%$ of samples are satisfactory (contamination rate less than or equal to $3 \mathrm{~m} . \mathrm{m}=5.10^{2}$ );

$\checkmark \quad 0.5 \%$ are acceptable;

Lack of unsatisfactory results.

\subsubsection{Staphylococcus Suspected Pathogens and ASR at $46{ }^{\circ} \mathrm{C}$}

The pathogenic Staphylococci were found in a single sample at a rate of $1.4 \times 10^{2}$ germs $/ \mathrm{g}$ which was less than $3 \mathrm{~m}\left(\mathrm{~m}=10^{2}\right.$ being the benchmark); Therefore, satisfactory.

\subsubsection{Salmonella}

Salmonella was not found in the samples.

\subsubsection{Synthesis of Analytical Results}

The overall results are shown in Table 4 . Averages are calculated from all encrypted values.

Table 4. Overall assessment of results

\begin{tabular}{lllllll}
\hline \multirow{2}{*}{ Germs } & Value & & \multicolumn{3}{c}{ Results (\%) } \\
& Minimum & Maximum & Averages & S & A & NS \\
\hline Total flora & $10^{2}$ & $48 \times 10^{5}$ & $1.1 \times 10^{4}$ & 89 & 1 & 10 \\
Fecal coliforms at $44^{\circ} \mathrm{C}$ & 10 & $3 \times 10^{4}$ & 60 & 63 & 2 & 35 \\
Staphylococcus suspected pathogens & - & - & - & 100 & 0 & 0 \\
Anaerobes sulfito-reducting agents & - & - & - & 99 & 0 & 1 \\
Fungic flora & 10 & $41 \times 10^{2}$ & $4 \times 10^{2}$ & 95 & 5 & 0 \\
Salmonella & - & - & - & 100 & 5 & 0 \\
Final result & - & - & - & 100 & 0 & 0 \\
\hline
\end{tabular}

$\mathrm{S}=$ Satisfactory; $\mathrm{A}=$ Acceptable; $\mathrm{NS}=$ Unsatisfactory.

The interpretation of the results is done according to a 3-class plan according to the reference criterion $\mathrm{m}$. If the values found are less than or equal to $3 \mathrm{~m}$, the result is considered satisfactory; If the values are between $3 \mathrm{~m}$ and $10 \mathrm{~m}$ inclusive the result is acceptable; If the values are greater than $10 \mathrm{~m}$, the result is unsatisfactory. For Salmonella, the interpretation is made according to a 2 class plan. "Absence": the quality is satisfactory "Presence": the quality is not satisfactory. 


\section{Macrothink}

\subsection{Discussion}

\subsubsection{Critting of Methodology}

\subsubsection{With Respect to Laboratory Techniques}

The microbiological analyzes were carried out, according to methods of analysis standardized in the laboratory of food microbiology of the EISMV of Dakar. The real effectiveness of the protocols used to attenuate it "bacterial stress" before cultivation remains unknown; the physiological mechanism of bacterial stress is still poorly understood. It should also be noted that the laboratory microbiological examinations did not involve an exhaustive search of all pathogens that could contaminate food. Major poisoning agents such as Campylobacter have not been investigated.

\subsubsection{Compared to Microbiological Criteria}

The results were interpreted in the light of the limits set by French standards (République Française, 2006). But this text, according to some experts (Hamza et al., 1999; ISO 6579, 2002), does not take into account Knowledge in the field of microbiology.

\subsubsection{Discussion of Results}

\subsubsection{Total Aerobic Mesophile Flora at $30{ }^{\circ} \mathrm{C}$}

The total flora gives information on the property of the manipulations, the conditions of conservation, the efficiency of the treatment processes, the freshness of products (Rozier et al., 1985). It remains the best indicator of the application of good hygienic practices (ISO 6579,2002 ). According to the standards, the most contaminated samples are those with a total flora content of more than $3.10^{6}$ germs $/ \mathrm{g}$ and are considered unsatisfactory. This result is superior to that found by Diabate (1991): 0\%; Alassane (1988): 2.27\% and Sylla (2000): 4\%. This would involve significant contamination of foodstuffs in poorly maintained storage areas, but also in the environment of the cooking place (outdoor cooking). On the other hand, our results are lower than those found by Seydi Dansou (2009).

\subsubsection{Fecal Coliforms}

The frequency of thermo-tolerant coliforms at $44{ }^{\circ} \mathrm{C}$ is indicative of fecal contamination. These are the genera: Enterobacter, Citrobacter, Klebsiella and narrow Escherichia coli. Our results abound towards those of Nifaoui (2015) who reported this germ. It also encountered the following germs: Citrobacter, Enterobacter and Klebsiella. The results show that they are involved in $35 \%$ of unsatisfactory samples. This result is comparable to that found by Alassane (1988): 35.71\%, Namkoisse (1990): 35\% and Hamza (1999): 35.63\%. This is explained by the similarity of the problems encountered (lack of staff training, lack of control...).

However, it is considerably higher than that found by Sylla (2000) 9\% and Diabate (1991) $18.64 \%$. This could be explained, on the one hand, by contamination by staff. Indeed, there are no washbasins and soaps at the exit of the toilets, in addition, the cooks, very often, handle the meats after cooking and distribute them of their hands to the different bowls. Other researchers (Seydi, 2009) found a 3\% annual percentage while in Algeria (Sylla, 2003) and in Belgium the contamination was relatively low, i.e. $1.5 \%$ and $1.02 \%$. Contamination can occur from equipment, and the environment since a gigantic tree refuge of many birds, overhang the pots, metal containers in the cooking area. The contamination will be through the faeces of these birds, which are detached from the tree to deposit on the commodities. Seydi Dansou (2009) 


\section{MInstitute ${ }^{\text {Macrothink }}$}

reported a $100 \%$ satisfaction rate compared to Yoro et al. (2003) who obtained a rate of $43 \%$ and Sylla and Seydi (2003) who obtained a satisfactory rate of $84 \%$. The observations made during the investigations on the poor conditions of conservation of the materials.

\subsubsection{Presumed Pathogenic Staphylococci}

These germs are generally assimilated to Staphylococcus aureus. They are of human origin (skin, hair, nostrils and mouths) and show insufficient hygiene. These germs were found in a single sample at a rate of $1.4 .10^{2} / \mathrm{g}$, thus satisfying according to standards. These results show that suspected pathogenic Staphylococci are not involved in the nonconformity of the samples. Our results are comparable to those found for hot meals by Alassane (1988) and Diabate (1991). The low rate where the absence of pathogenic Staphylococci in the samples is explained by their inhibition by other microorganisms (Nifaoui, 2015; Fleurette, 1991) reported that these bacteria contaminate meat with hams, salads, cakes when handling is frequent. In the end, did not mention any contamination by Staphylococci in hospital foods (Barbara et al., 2009).

\subsubsection{Sulfite-Reducing Anaerobes at $46{ }^{\circ} \mathrm{C}$}

Clostridia usually occurs in spores in the external environment (soil, dust, excrements...). The results of the analyzes showed that ASRs are counted in one sample out of 100, at a high (incompatible) rate of which unsatisfactory. The contamination could be from environmental sources, but also from personnel. Indeed, according to Namkoisse (1990) argued that the hands of cooks contain ASR. Nifaoui (2015) reported that spores are very resistant to heat and can thus alter the quality of the food products causing bad taste and bad odors (Diouf, 2001; Denis, 2014).

\subsubsection{Presumed Pathogenic Staphylococci}

These germs are generally assimilated to Staphylococcus aureus. They are of human origin (skin, hair, nostrils and mouths) and show insufficient hygiene. These germs were found in a single sample at a rate of $1.4 .10^{2} / \mathrm{g}$, thus satisfying according to standards. These results show that suspected pathogenic Staphylococci are not involved in the nonconformity of the samples. Our results are comparable to those found for hot meals by Alassane (1988) and Diabate (1991). The low rate where the absence of pathogenic Staphylococci in the samples is explained by their inhibition by other microorganisms (Nifaoui, 2015; Fleurette, 1991) reported that these bacteria contaminate meat with hams, salads, cakes when handling is frequent. In the end, did not mention any contamination by Staphylococcus in hospital foods (Barbara et al., 2009).

\subsubsection{Sulfite-Reducing Anaerobes at $46{ }^{\circ} \mathrm{C}$}

Clostridia usually occurs in spores in the external environment (soil, dust, excrement ...). The results of the analyzes show that ASRs are counted in one sample out of 100, at a high (incompatible) rate of which unsatisfactory. The contamination could be from environmental sources, but also from personnel. Indeed, according to Namkoisse (1990) argued that the hands of cooks contain ASR. Nifaoui (2015) reported that spores are very resistant to heat and can thus alter the quality of the food products causing bad taste and bad odors (Diouf, 2001; Denis, 2014). 


\section{Macrothink}

\subsubsection{Salmonella}

Salmonella ensure their perennially in the digestive tract of warm-blooded and cold-blooded animals. They may multiply in the external environment; their survival is of long duration. No salmonella could be detected in contrast to Hamza et al. (1999) and Nifaoui (2015). However, the high incidence of fecal coliforms causes a high degree of suspicion, as the survival of fecal coliforms in the environment is similar to that of Salmonella. As shown by Catsaras and Grebot (1984), Salmonella can be negatively detected by the classical method even though the sample contains $10^{5}$ to $10^{8} \mathrm{germs} / \mathrm{g}$. This fact is linked in their opinion to the presence of inhibitory germs (coliform, Proteus). The following authors Zbadi et al. (2014) in Morocco, Yousif et al. (2013) who worked on chickens and finally Lues et al. (2013) who worked in South Africa in hospital did not report any cases of contamination not salmonella with the exception of Yousif (2013), which reported a relatively low infection rate of $1 \%$ of chickens by Salmonella pullorum gallinarum.

\subsubsection{Fungic Flora (Yeasts and Molds)}

Unsatisfactory results have not been found. However, this flora is present in $58 \%$ of the samples. This is due to low environmental contamination. On the other hand, Geotrichum and Candida and Saccharomyces cereviciae are found in food (Ablad, 2010). Those are filamentous microorganisms that are disseminated by the emission of spores (Seydi, 2009).

\subsubsection{Overall Results}

Forty-one percent of meals were unsatisfactory (Figure 1). These results were superior to those found by Sylla (2000): 12\%. This is explained by the many manipulations experienced by foods associated with poor hygiene conditions. These results are, however, much lower than those found by Diabate (1991): $72.06 \%$.

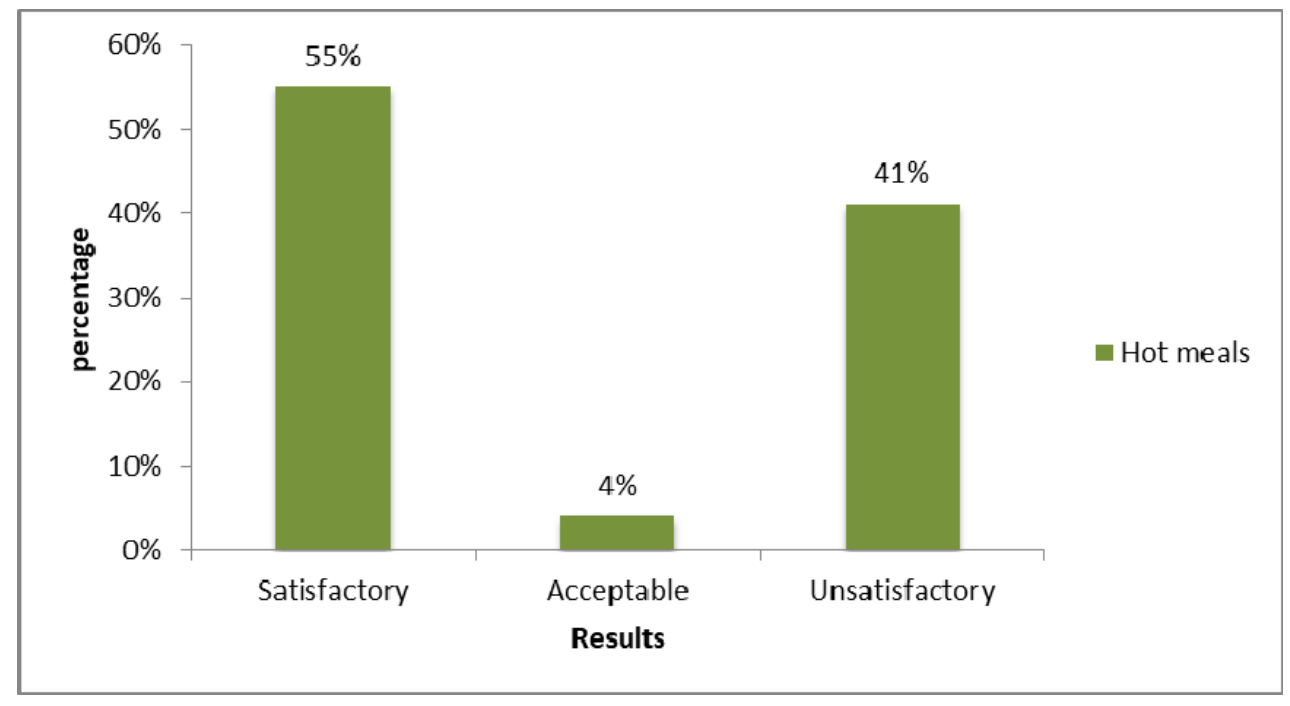

Figure 1. Overall results of microbiological analyzes (\%)

\section{Conclusion}

Restoration as an economic activity is very recent in Africa. Several factors contribute to the development of commercial and collective catering. In hospital catering, this risk is greater. 


\section{Macrothink}

But this increase, which also concerns social catering (university, hospital, etc.), results in non-compliance with basic hygiene measures during food preparation and exposes consumers to the risk of toxic infections.

The study showed that, the patient, because of his disease, is more susceptible to the poisonings than the other layers of the population. This means that foods prepared under less stringent hygiene rules can infect or poison it, whereas this would not be the case in a healthy population. It is therefore important that strict hygiene rules be observed in kitchens where meals are prepared for healthcare facilities.

This study concludes that the rate of bacterial contamination of meals is quite high especially what is fecal coliforms. Prevention of food-borne diseases will involve improving product safety through increased involvement of health services at all stages; continuous monitoring of contaminants in food; over their promotion of food quality control and finally education and information on staff in food hygiene and product safety.

\section{Conflict of Interest}

The authors declare that they have no conflicts of interest in relation to this article.

\section{References}

Ablad, A. (2010). Microbiological analysis of foods (p. 38). DEA Memory. Faculty of Sciences and Technology of Fez.

Adams, M. R., \& Moss, M. O. (2008). Food Microbiology (3rd ed.). Cambridge, UK: The Royal Society of Chemistry.

Alassane, A. (1988). Contribution to the study of hygiene in collective catering at the Center for University Works in Dakar (Coud).

Assmi, H., Bechina, Z., \& Ouargl, A. (2005). Etudes de prévalence sur les infections nosocomiales dans quelques services de l'hôpital Mohamed Boudiaf.

Barbara, M. L., \& Sarah, J. O'brien. (2009). Microbiological safety of food in hospitals and others healthcare settings. Journal of Hospital Infection, 73, 109-120. https://doi.org/10.1016/ j.jhin.2009.05.017

Bhattarai, J., \& Yadav, A. (2018). Knowledge regarding maintenance of food safety among food handlers at canteens of a tertiary level hospital of Eastern Nepal. Paripex-Indian Journal of Research, 7(3), 92-96.

Catsaras, M., \& Grebot, D. (1984). Multiplication of salmonella in minced meat. Bull. Acad. Vet. France, 57, 501-502. https://doi.org/10.4267/2042/65006

Denis, C. (2014). Biological hazards of food; Food-borne infections and TIAC. Envt. http://Corpet.net./Denis.

Diabate, V. (1991). Contribution to the study of hygiene in collective catering in Côte d'Ivoire: Case of the University Hospital Center (UHC) of Cocody d'Abidjan. Th. Méd. Vet. EISMV, Dakar.

Diouf, C. (2001). Microbiological and chemical analysis of fisheries.

Fleurette, J. (1991). Staphylococcal food poisoning. Paris, 547, 23-25.

Hamza, R., Naffati, L., Kamoun, H., Dhaouadi, M., Akrout, A., Graza, A., \& Graza, W. (1999). Contribution to the study of food behaviors in hospitals: About a preliminary survey 
of in patients. Rev. Microb. Hyg. Ali, 11, 31-34.

Lues, J. F. R., Setlare, G. G., Shale, K., \& Malebo, N. J. (2013). Microbial levels on the food preparation areas of a typical district hospital in South Africa. African Journal of Microbiology Research, 7(24), 2998-3008. https://doi.org/10.5897/AJMR2013.5796

Namkoisse, E. (1990). Hygiene of the collective catering at the Center of the University Works of Dakar (Coud): Case of the new restaurant called Argentine.

Nicolas, M. (2008). Day romande des répondants en hygiène des établissements de soins. Institut de lavigny, 1115.

Nifaoui, Z. (2015). Microbiological control of foods served in a hospital setting at Fez. Bachelor of Sc, University Sidi Mohamed Ben Abdallah.

Normes ISO (2002). Microbiologie des aliments: Méthodes horizontales pour la recherche des salmonelles (p. 27).

Rozier, J., Carliet, V., \& Bolnot, F. (1985). Microbiological Baits of Food Hygiene. Paris Sepaic.

Seydi, D. S. (2009). Study of the microbiological quality of the meals served at the level of the center of the university works of Dakar (Coud) Med. Clothes.

Sharif, L., Obaidat, M. M., \& Al-Dalalah, M. R. (2013). Food Hygiene Knowledge, Attitudes and Practices of the Food Handlers in the Military Hospitals. Food and Nutrition Sciences, 4, 245-251. https://doi.org/10.4236/fns.2013.43033

Sylla, K. S., \& Seydi, M. (2003). Study of the hygienic quality of fish used in restoration University collection in Dakar (Senegal). RASPA, 1, 17-23.

Sylla, K. S. B. (2000). Contribution à l'étude comparée des conditions de réception de stockage et de préparation des denrées alimentaires d'origine animale dans la restauration collective : Cas des Restaurations du Centres des Euvres Universitaires de Dakar (COUD)Sénégal.

Yoro, N., Kou, A., \& N'gbakou, D. (2003). Review of microbiological analyzes of foods in Abidjan from 1990 to 1995. Microbiology, Food Hygiene, 15(44), 31-39.

Yousif, E. L., Ashoush, D. A., \& Haagoma, K. A. (2013). Critical control points for preparing chicken meals in a hospital kitchen. Animals of Agricultural Science, 58(2), 203-211. https://doi.org/10.1016/j.aoas.2013.07.004

Zbadi, L., El Ouali Lalmi, A., Marsou, Z., \& Fikri, B. K. (2014). The results of this study are presented in the literature. Journal of Advances in Biotechnology, 4(1), 286. https://doi.org/ 10.24297/jbt.v4i1.1629

\section{Copyright Disclaimer}

Copyright for this article is retained by the author(s), with first publication rights granted to the journal.

This is an open-access article distributed under the terms and conditions of the Creative Commons Attribution license (http://creativecommons.org/licenses/by/3.0/). 